\title{
Forecasting bark beetle early flight activity with plant phenology
}

\author{
C. Zang $^{1,2}$, R. Helm ${ }^{1}$, T. H. Sparks ${ }^{1,3,4,5}$, A. Menzel ${ }^{1,3, *}$ \\ ${ }^{1}$ Ecoclimatology, Technische Universität München, Hans-Carl-von-Carlowitz-Platz 2, 85354 Freising, Germany \\ ${ }^{2}$ Biological and Environmental Sciences, School of Natural Sciences, University of Stirling, Stirling FK9 4LA, UK \\ ${ }^{3}$ Institute for Advanced Study, Technische Universität München, Lichtenbergstraße 2a, 85748 Garching, Germany \\ ${ }^{4}$ Institute of Zoology, Poznan University of Life Sciences, Wojska Polskiego 71C, 60-625 Poznan, Poland \\ ${ }^{5}$ Sigma, Coventry University, Priory Street, Coventry CV1 5FB, UK
}

\begin{abstract}
Bark beetle outbreaks are a major threat to forest productivity, and a robust forecast of early flight activity is necessary for inhibition or mitigation of large-scale infestations. We used spring phenology of common wild plants in a phenology-based forecasting approach for European spruce bark beetle Ips typographicus L. early flight activity in Bavaria, Southern Germany, and tested this novel approach against traditional thermal sum-based predictions. Our phenologybased forecast employing the 2 phenological phases of first flowering of common snowdrop Galanthus nivalis L. and leaf budburst of horse chestnut Aesculus hippocastanum L. proved to be more robust and accurate than the thermal sum-based forecast. This is explained by both bark beetle phenology and plant phenology being results of a complex control chain of environmental factors, which can be approximated by temperature sums only to a limited degree. However, our space-for-time approach demonstrates strong and unequivocal temperature sensitivity of bark beetle and plant phenology. This indicates a common pattern in bioclimatic mediation of ecophysiological processes for both plants and insects as the mechanistic foundation for forecasting. In the case of costly bark beetle activity monitoring data often characterised by gaps and irregular sampling intervals, plant phenology can thus provide an easily observable alternative or complementary predictor for early flight activity. Our results indicate that forest practitioners can benefit from simple phenological observations to improve the timing of adequate management measures to mitigate bark beetle mass infestations.
\end{abstract}

KEY WORDS: Bark beetle - Ips typographus - Phenology - Galanthus nivalis - Aesculus hippocastanum $\cdot$ Linear mixed effects model

\section{INTRODUCTION}

It is estimated that 3 million $\mathrm{m}^{3}$ of wood were damaged by bark beetles annually between 1950 and 2000 in Europe (Schelhaas et al. 2003). The high financial penalties resulting from the inevitable sanitary fellings have encouraged infestation research to address the future consequences of changed pest pressure as well as to establish efficient monitoring schemes for bark beetles.

\footnotetext{
${ }^{*}$ Corresponding author: amenzel@wzw.tum.de
}

The European spruce bark beetle Ips typographus $\mathrm{L}$. is one of the major tree-killing bark beetles in Eurasia (Öhrn et al. 2014). The adults hibernate in forest litter and host trees. Under favourable conditions in spring, they search for vulnerable host trees, aggregate by pheromones, burrow through the weakened bark, mate and lay eggs in tunnels built in the inner bark and phloem. After a few weeks, sibling broods are likely. One (Northern Europe) to two generations (Central Europe) are common, and in

(C) The authors 2015. Open Access under Creative Commons by Attribution Licence. Use, distribution and reproduction are unrestricted. Authors and original publication must be credited. 
warm years, even a third generation is possible. Thus, their population dynamics are altered by 2 temperature-related factors: (1) winter mortality, which can dramatically reduce populations, especially in Northern Europe (Annila 1969), (2) duration of development in terms of timing of swarming (mainly controlled by thermal sums) and voltinism (i.e. the number of generations produced in a year, mainly controlled by temperature and photoperiod; Bakke 1992, Jönsson \& Bärring 2011). Similarly, the responses of native bark beetles in western North America to warming differ depending on temperature-dependent life-history strategies, including cold-induced mortality and developmental timing (Bentz et al. 2010).

I. typographus is among the most serious pests of Norway spruce Picea abies (L.) Karst. In south-eastern Germany, Norway spruce is by far the economically most important tree species and has often been planted at the margin of, or outside, its native range where the species is not adapted to soil and climate conditions (Brosinger \& Östreicher 2009). As a consequence of climate change, bark beetle attacks are more likely to occur in Norway spruce because of worsened average growing conditions (Spellmann et al. 2007, Hanewinkel et al. 2013) and more frequent exposure to extreme climatic events (Beniston 2004, Lindner et al. 2010), rendering trees more susceptible to wind throw and insect pests (Schlyter et al. 2006). Decreasing vitality and increasing mortality of Norway spruce are then likely to increase the amount of breeding material and to foster bark beetle mass propagation, as the record-breaking bark beetle infestations after the Central European drought year of 2003 suggested (Rouault et al. 2006).

Projections even in a moderately altered climate (period 2071-2100, scenario B1, Spekat et al. 2007) suggest that in south-eastern Germany in the future, large areas at lower altitudes will be high-risk areas for Norway spruce cultivation (Kölling et al. 2009). As a consequence, Norway spruce will have to overcome the combined effect of a changing climate and its extremes in concert with intensified bark beetle population outbreaks.

As a consequence, a functional monitoring system is of pivotal interest for forest practitioners who need to apply relevant measures in a timely fashion to inhibit or attenuate outbreaks. Such measures include intensified monitoring of standing wood, removal of infested trees and breeding material such as dead wood, and insecticide application to stored wood. The onset of bark beetle activity in spring is thus a critical date, which has been a focus of ento- mological research for decades. For example, Öhrn et al. (2014) reported region-specific flight patterns for Sweden and concluded that the understanding of key factors for emergence would facilitate efficient pest management and improve models of population dynamics. In the case of I. typographus, its spring swarming has been intensively investigated by numerous researchers in Europe (Annila 1969, Zumr 1982, Harding \& Ravn 1985, Lobinger 1994, Wermelinger \& Seifert 1998, Faccoli 2009, Öhrn et al. 2014), focussing on the minimum temperature threshold for flight activity and the thermal sums needed for beetle development stages. Most of these studies employ spatially and/or temporally highly resolved data sets for bark beetle development.

In the early 1990s, a few German forest authorities started to monitor the annual flight activities of I. typographus and other bark beetle species using pheromone traps in order to provide forest owners and managers with actual information on the local exposure of forest stands to bark beetles. The quality of these data, especially in terms of observation frequency, varies with local responsibility for data collection, but also with other factors, such as accessibility of the traps. Our goal in this study was to develop a forecasting model for bark beetle early emergence based on Bavarian trap count data.

Since local temperature sums and temperature thresholds are not directly available to forest practitioners, we tested the suitability of phenological observations of a few common wild species as early warning indicators of $I$. typographus spring flight activity. Observational evidence based on long-term phenological records clearly reveals that recent warming has led to an earlier onset of spring events and to a prolonged season, both for plants (in terms of earlier leaf unfolding and flowering and a longer growing season; e.g. Menzel et al. 2006) as well as for insects (in terms of earlier appearance and longer period of activity; e.g. Roy \& Sparks 2000, Walther et al. 2002, Parmesan \& Yohe 2003, van Asch \& Visser 2007). Since an important component in modelling both insect and plant phenology are thermal requirements, we hypothesized that plant spring phenology might be used as an easily and cheaply obtainable indicator of bark beetle spring flight activity.

Consequently, in this study we asked (1) whether plant spring phenology is correlated with bark beetle early emergence, (2) which plant phenological phases are suitable for modelling bark beetle spring flight activity and (3) whether a phenology-based forecast performs better or worse than a forecast based on thermal requirements. Using a split-calibration 
approach within a Monte-Carlo resampling scheme, we show that predictions based on 2 spring phenophases, viz. first flowering of common snowdrop Galanthus nivalis L. and leaf budburst of horse chestnut Aesculus hippocastanum L., generate more precise and robust forecasts of bark beetle early flight activity than a traditional thermal sum-based approach.

\section{MATERIALS AND METHODS}

\subsection{Study area}

The study area spans the federal state of Bavaria, Germany (Fig. $1 ; 47^{\circ} 17^{\prime}$ to $50^{\circ} 33^{\prime} \mathrm{N}$ and $8^{\circ} 59^{\prime}$ to $13^{\circ} 50^{\prime}$ E). Bavaria covers $70550 \mathrm{~km}^{2}$ and has a humid continental climate with warm summers. Between 1971 and 2000, the annual mean temperature was $7.8^{\circ} \mathrm{C}$ and the mean annual precipitation was $940 \mathrm{~mm}$ (German Meteorological Service). Approximately one-third of Bavaria is covered by forest, of which $44 \%$ consists of Norway spruce (www.bundeswald inventur.de).

\subsection{Insect trapping}

From 2006 to 2011, Ips typographus was monitored using pheromone-baited slot traps (Friedrich Theysohn Kunststoff). The installation and monitoring of

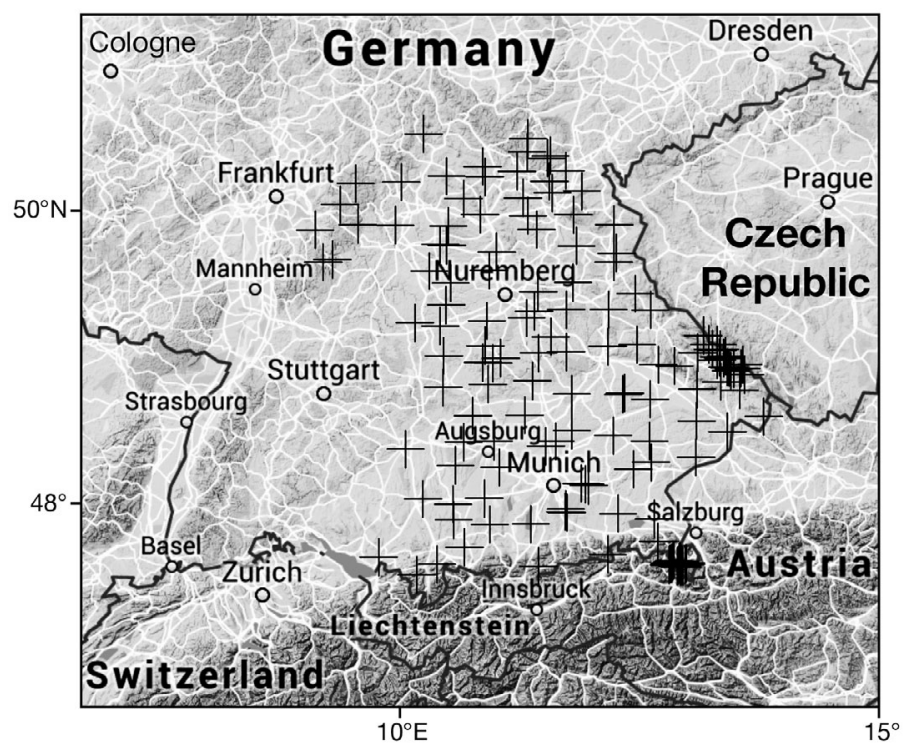

Fig. 1. Geographic distribution of the European spruce bark beetle Ips typographus trap sites in Bavaria, Germany, used in this study $(\mathrm{n}=243)$ beetle traps was done by forestry staff in private, municipal and state forests. Traps were mainly installed in pairs and located at sunny sites in clearings or in clear-cuts about $25 \mathrm{~m}$ from the edge of forests characterised by a minimum cover of $50 \%$ Norway spruce. Trap sites had an altitudinal range from 185 to $1498 \mathrm{~m}$ above sea level (a.s.l. median $=510 \mathrm{~m}, 70$ trap sites above $1000 \mathrm{~m}$ a.s.l.). The slot traps were baited with a Pheroprax ${ }^{\circledR}$ ampoule (BASF SE). Trapping took place every year from the beginning of April until (on average) the end of August. Pheromone ampoules were replaced on average every 6 wk during the annual monitoring period. Collection intervals varied greatly between traps, often reflecting accessibility. In this study, we only considered data series from traps visited at least 15 times (median $=22$ ) a year and with a total trap count of more than 1000 beetles; thus, $28 \%$ of time series were excluded. We assumed that the retained traps would provide more reliable phenological information. Most traps were recorded weekly, but a few traps were recorded more frequently; 1 trap was inspected almost daily. The number of trap series analysed was 1186, based on 204, 213, 206, 222, 141 and 200 traps for the years 2006-2011, respectively.

Visual inspection of the trap data revealed that it was impossible to separate each series into parent and offspring generations as undertaken by e.g. Baier et al. (2007) and Faccoli (2009). An algorithm to automate this process of separating generations was equally unsuccessful. In addition, no differentiation into males and females was provided for the trap counts. Consequently, we focus in this paper on early flight activity of the beetles. The day of the year (DOY) on which the first beetle was trapped (herein after the 'first beetle date', FBD) was derived for each trap series. The date of the first event is commonly used in phenological studies (e.g. Harrington et al. 2007, Ellwood et al. 2012). Due to the sampling intervals, FBD in our study has a maximum bias of around $1 \mathrm{wk}$ in 1 direction, i.e. the true FBD could have occurred up to $7 \mathrm{~d}$ before the recorded FBD.

\subsection{Climate data}

For 2006-2011, we used meteorological data from 130 weather stations of the German Meteorological Service within the study area. Daily mean air temperatures for trap sites were estimated by interpolation of data from individual weather stations within a $100 \mathrm{~km}$ radius using an inverse distance weighting method with squared inverse distances and sea-level correction similar to Müller-Westermeier (1995). 


\subsection{Plant phenology}

Corresponding phenological data from 23 plant species for the period 2006-2011 were studied. The data set, consisting of about 60164 single observations, was provided by the German Meteorological Service and contains onset dates of leaf and flower development stages, mainly collected by voluntary plant observers. The investigated plant species include trees, but also a few shrubs, a herb and a grass species. The data were spatially interpolated and assigned to the bark beetle trap sites in the same manner as undertaken for the meteorological data. For the phenological data, a maximum bias of 1 to $2 \mathrm{~d}$ later reporting than actual occurrence can be assumed (DWD 1991).

\subsection{Prediction of FBD}

To test the performance of a phenology-based prediction for bark beetle early flight activity against a thermal sum-based prediction, we used a 2-step modelling approach. Within a Monte-Carlo resampling scheme with 250 replications, we divided the full set of FBD dates into 2 equally sized parts for calibration and validation.

With the calibration data set, we computed thermal sums $\left(\mathrm{T}_{\mathrm{DD}}\right)$ expressed as degree-days (dd), related to the DOY of FBD for each trap in the calibration set, and set the robust biweight mean (Mosteller \& Tukey 1977) over all traps as the global $\mathrm{T}_{\mathrm{DD}}$ for the specific validation run. $\mathrm{T}_{\mathrm{DD}}$ was computed as the temperature sum for all preceding days with a mean temperature above the threshold of $7^{\circ} \mathrm{C}$ since 1 January suitable for Central Europe (Annila 1969). For the validation, we computed for each trap in the validation set the DOY for the predicted FBD according to $\mathrm{T}_{\mathrm{DD}}$. To assess the prediction quality, we computed the residual sum of squares (RSS), the goodness of fit for the validation period $\left(\mathrm{R}^{2}\right)$, the deviations of predictions from observations in days (DEV), as well as the reduction of error (RE) and the coefficient of efficiency (CE) as 2 metrics for assessing forecasting skills (Cook et al. 1994). For both RE and CE, a higher value signifies a better model, and a value $>0$ indicates that the forecast is better than the mean of the observational data in the calibration set (RE) or, more rigorously, in the validation set (CE).

We additionally tested the sensitivity of the $\mathrm{T}_{\mathrm{DD}}$ based modelling approach to the temperature threshold. For this run, we used the threshold of $5^{\circ} \mathrm{C}$ suitable for Northern Europe (Annila 1969), since a considerable part of the trap sites were located at medium to high elevations.

The same sets were used for developing phenologybased predictions of FBD based on 2 phenophases. Candidate phenophases for this modelling approach had to (1) generally occur before mean FBD, (2) be frequently observed and (3) correspond to species with a wide distributional range. The 9 phenophases matching these criteria were: common snowdrop Galanthus nivalis L. (first flowering), common hazel Corylus avellana L. (first flowering), Cornelian cherry Cornus mas L. (first flowering), border forsythia Forsythia $\times$ intermedia (first flowering), horse chestnut Aesculus hippocastanum L. (leaf budburst), mountain-ash Sorbus aucuparia L. (leaf budburst), silver birch Betula pendula Roth. (leaf budburst), European larch Larix decidua Mill. (needle unfolding) and Norway maple Acer platanoides L. (first flowering).

We fitted linear mixed effects models on the calibration set using the observation years as random effects. To identify the best phenological predictors of FBD, we used all possible combinations of 2 phenophases to fit models of the form

$$
\begin{aligned}
\widehat{\text { FBD }}_{i j}= & \beta_{0}+\beta_{1} \times \text { phase }_{i j}+\beta_{2} \times \text { phase } 2_{i j}+u_{0 j}+u_{1 j} \\
& \times \text { phase }_{i j}+u_{2 j} \times \text { phase } 2_{i j}+\varepsilon_{i j}
\end{aligned}
$$

where $\widehat{\mathbf{F B D}}_{i j}$ is the estimate of the variable vector containing the FBD for beetle trap $i$ and year $j, \beta_{0} \ldots$ $\beta_{2}$ are fixed effects associated with the intercept and the 2 phenophases, $u_{0} \ldots u_{2}$ denote the random observation year effects associated with the intercept and the slopes for the 2 phenological phases, and $\varepsilon_{i j}$ corresponds to the residuals. The resulting 36 models were ordered with respect to Akaike's information criterion (AIC), and the best model was selected based on the lowest AIC.

For the validation runs, we used the fixed effects for the best model on the validation set to generate a prediction for the DOY of FBD based on phenological observations of the 2 phenophases used in the specific model. For comparison of approaches, we computed RSS, $\mathrm{R}^{2}, \mathrm{RE}, \mathrm{CE}$ and $\mathrm{DEV}$ as for the $\mathrm{T}_{\mathrm{DD}}$-based approach. The comparison of validation metrics between models was performed using paired 1-sided Wilcoxon signed rank tests.

For the practical purposes of predicting FBD based on phenological field observations, we derived a simplified phenology-based model from the median of the fixed effects over all calibration runs as:

$$
\widehat{\mathbf{F B D}}=\beta_{0}+\overline{\beta_{1}} \times \mathrm{DOY}_{\text {phase } 1}+\overline{\beta_{2}} \times \mathrm{DOY}_{\text {phase } 2}
$$

The effect sizes of the 2 phenophases for the simplified model were computed as Cohen's $d$ based on 
the median fixed effects coefficients divided by the standard deviation of the corresponding independent variable.

Since the use of linear mixed effects model is statistically advised for phenology-based forecasting models, but no comparable consideration of the longitudinal data structure was possible for the $\mathrm{T}_{\mathrm{DD}}$-based modelling approach, we tested for a potential advantage of including mixed effects. To this end, we additionally fitted simpler linear models without random effects using the same parameter selection process outlined above.

\subsection{Temperature sensitivity of FBD and phenology}

Since we employed a space-for-time approach as far as predictions of FBD changes with changing temperatures are concerned, an assessment of temperature sensitivity for the study data set was essential. We used the mean temperature for the $30 \mathrm{~d}$ preceding the first decile of all FBD observations (T30) to model the sensitivity of FBD to temperature with a linear mixed effects model of the form

$$
\widehat{\mathbf{F B D}}_{\mathrm{ij}}=\beta_{0}+\beta_{1} \times \mathrm{T} 30_{i j}+u_{0 j}+u_{1 j} \times \mathrm{T} 30_{i j}+\varepsilon_{i j}
$$

where $\beta_{0}$ and $\beta_{1}$ are fixed effects associated with intercept and T30, $u_{0}$ and $u_{1}$ denote the random observation year effects associated with the intercept and the slope for T30, and $\varepsilon_{i j}$ corresponds to the residuals. Since FBD observations have a potential bias (see section 2.2 above), we additionally tested the robustness of the sensitivity estimate in a bootstrapping scheme. In 1000 iterations, we subtracted random biases between 0 and $7 \mathrm{~d}$ from the FBD observations and fitted models of the same form as above. Confidence intervals $(95 \%)$ for the true sensitivity were then derived from the 2.5th and 97.5th percentiles of the fixed effects estimates for the regression slopes.

Sensitivity of the selected phenophases was similarly modelled, with T30 also set to the mean temperature of the $30 \mathrm{~d}$ preceding the lower first decile of all observations for the respective phenophase. For comparison of lapse rates, we used the fixed effects of the sensitivity models for FBD and phenology. Goodness of fit for all sensitivity models was computed using Johnson's (2014) extension of the Nakagawa \& Schielzeth (2013) marginal $\mathrm{R}^{2}$ giving the proportion of variance explained by fixed effects alone in a mixed effects model.

To test for potential altitudinal effects on sensitivity, we additionally computed models after stratifying the data into 4 altitudinal belts: colline and submon- tane $(<450 \mathrm{~m})$, lower montane (450-650 m), medium montane (650-800 m) and high montane (800$1500 \mathrm{~m}$ ) for German uplands (cf. Ellenberg 1996). For this stratified approach, T30 was computed individually for each altitudinal belt.

Computations were performed using $\mathrm{R}$ version 3.2.1 (R Development Core Team 2015) using packages lme4 (Bates et al. 2015), lmerTest (Kuznetsova et al. 2013), treeclim (Zang \& Biondi 2015), ggplot2 (Wickham 2009), ggmap (Kahle \& Wickham 2013) and $\mathrm{R}$ code for computing marginal $\mathrm{R}^{2}$ values for lme4 models (Lefcheck \& Casallas 2014).

\section{RESULTS}

\subsection{Modelled $T_{D D}$}

The mean modelled critical thermal sum $\left(\mathrm{T}_{\mathrm{DD}}\right)$ based on the random draws for the calibration subset for bark beetle first flight activity (FBD) using the $7^{\circ} \mathrm{C}$ threshold was $44.4 \mathrm{dd}$, with a $95 \%$ confidence interval of $41.6-46.7 \mathrm{dd}$.

\subsection{Phenology-based models}

Selection of phenophases was very robust within the 250 model selection iterations, with Galanthus nivalis (first flowering) being selected as 1 of 2 model components in $96 \%$ of the cases, and Aesculus hippocastanum (leaf budburst) being selected in $62 \%$ of the cases. Over half $(60 \%)$ of the models included both phases together. Acer platanoides (first flowering) was ranked third in importance for modelling and was selected in $33 \%$ of the models.

We derived a simplified phenology-based model for prediction of FBD as:

$$
\begin{aligned}
\widehat{\text { FBD }}= & 67+0.20 \times \mathrm{DOY}_{\text {G. nivalis first flowering }} \\
& +0.32 \times \mathrm{DOY}_{\text {A. hippocastanum leaf budburst }}
\end{aligned}
$$

The effect size of $A$. hippocastanum leaf budburst was 4 times greater than the effect size of $G$. nivalis first flowering, i.e. the sensitivity of $A$. hippocastanum leaf phenology to climate dominated the prediction of FBD with this phenology-based model.

\subsection{Comparison of modelling approaches}

The $\mathrm{T}_{\mathrm{DD}}$-based model displayed significantly larger deviations between predicted and observed FBD dates than the phenology-based model (RSS, $\mathrm{p}<$ 
0.001, Fig. 2), with a median improvement of ca. $3 \%$ for the phenology model over the $\mathrm{T}_{\mathrm{DD}}$ model. Consequently, the explained variance in FBD $\left(\mathrm{R}^{2}\right)$ in the validation period was significantly higher for the phenology model $(\mathrm{p}<0.001$, Fig. 2$)$, with a median increase of $18 \%$ in $\mathrm{R}^{2}$.

The most pronounced differences between the modelling approaches were found with respect to their respective forecasting skills. Both RE and CE were significantly higher for the phenological model ( $p<0.001$ in both cases, Fig. 2, lower half) with median differences of 0.14 for RE and 0.13 for CE. Moreover, both RE and CE were significantly greater than 0 for the phenology model ( $p<0.001,1$ sample 1-sided Wilcoxon rank test), indicating predictive skills better than the mean of the observed FBD in the calibration and validation period, respectively. In contrast, both RE and CE were significantly smaller than 0 for the $\mathrm{T}_{\mathrm{DD}}$ model $(\mathrm{p}<0.001)$. Thus, a forecast of FBD with this model was not better than the mean of the FBD observations.

On average, the phenology-based approach led to less bias in the determination of FBD (Fig. 3), with a median DEV of -0.10 d, i.e. a median forecast of FBD $0.10 \mathrm{~d}$ too early. The general bias tendency of the phe-
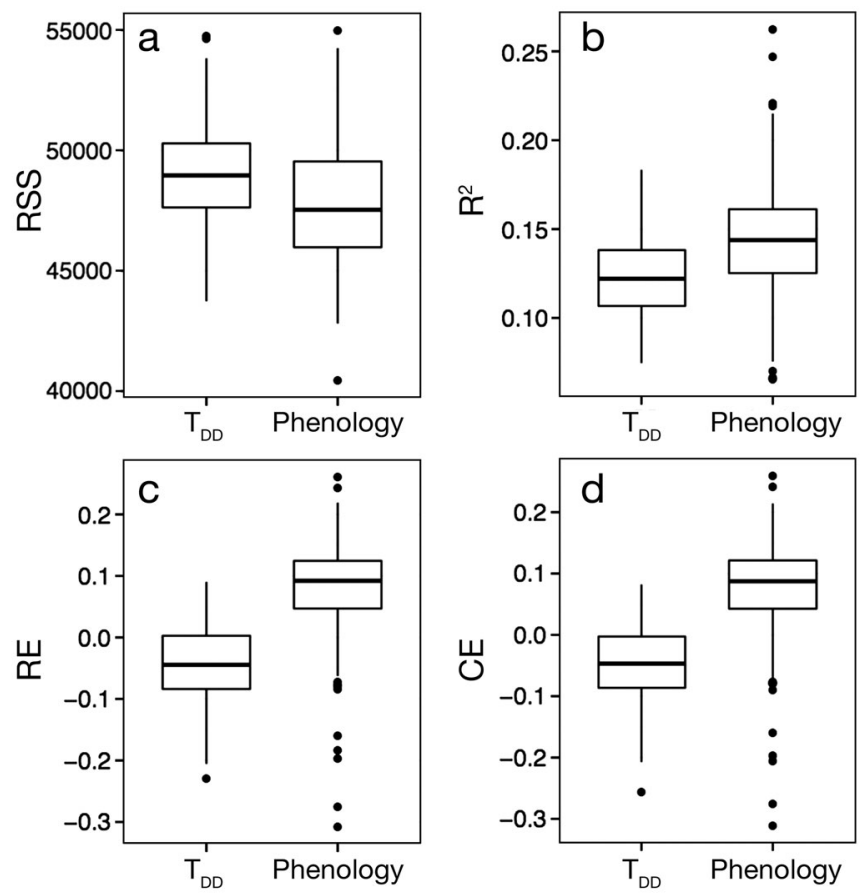

Fig. 2. Goodness of fit and forecasting performance metrics for thermal sums $\left(\mathrm{T}_{\mathrm{DD}}\right)$-based and phenology-based modelling of European spruce bark beetle Ips typographus early flight activity. Comparisons for (a) the residual sum of squares (RSS) and (b) the overall goodness of fit $\left(\mathrm{R}^{2}\right)$, both for the validation period, and (c) the reduction of error (RE) and (d) the coefficient of efficiency (CE)

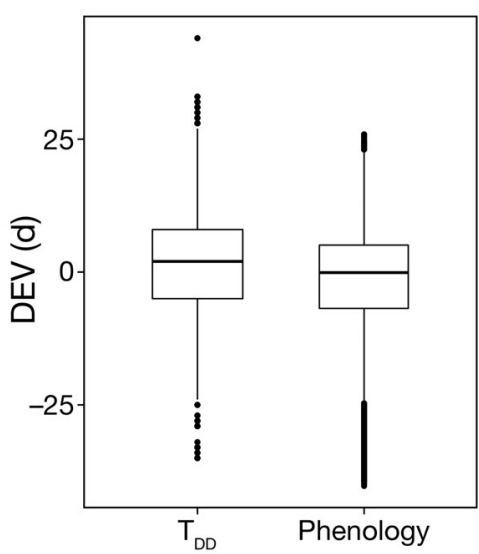

Fig. 3. Deviations of predictions from observations in days $(\mathrm{DEV})$ for the thermal sums $\left(\mathrm{T}_{\mathrm{DD}}\right)$-based and phenologybased modelling approaches

nology model was towards a too early forecast, with DEV being significantly smaller than $0(p<0.001)$. On the other hand, the median DEV for the $\mathrm{T}_{\mathrm{DD}}$-based model was $2.00 \mathrm{~d}$, resulting in a median forecast of FBD $2 \mathrm{~d}$ too late. For the $\mathrm{T}_{\mathrm{DD}}$ model, the general bias tendency was towards a too late forecast, with DEV being significantly greater than $0(\mathrm{p}<0.001)$.

\subsection{Sensitivity of FBD and plant phenology to mean temperature}

With increasing mean temperature prior to the lower first decile of observation dates, FBD was significantly earlier (Fig. 4A). The lapse rate signifies a shift of FBD to $2.6 \mathrm{~d}$ earlier per $1^{\circ} \mathrm{C}$ increase in T30 temperature. The fixed effect of T30 can explain $26 \%$ of the variance in FBD (marginal $\mathrm{R}^{2}$ of 0.26 ). With a rather narrow $95 \%$ confidence interval of -2.79 to $-2.47 \mathrm{~d}^{\circ} \mathrm{C}^{-1}$, the estimate of FBD sensitivity was relatively robust against a potential inaccuracy associated with the irregular temporal distribution of sampling dates.

The temperature sensitivity for both phenophases used for modelling was more pronounced, resulting in higher lapse rates and variance explained in observation dates by T30 (Fig. 4B,C). For G. nivalis, the lapse rate was $5.5 \mathrm{~d}$ earlier first flowering per $1{ }^{\circ} \mathrm{C}$ increase in T30, with a marginal $\mathrm{R}^{2}$ of 0.78 . For $A$. hippocastanum, the lapse rate amounted to $4.0 \mathrm{~d}$ earlier leaf budburst per $1^{\circ} \mathrm{C}$ increase in T30, with a marginal $\mathrm{R}^{2}$ of 0.72 .

The sensitivity of FBD and A. hippocastanum leaf budburst was very robust across altitudinal belts: we observed a gradual shift from $-2.6 \mathrm{~d}^{\circ} \mathrm{C}^{-1}$ in the colline and submontane belt to $-2.7 \mathrm{~d}^{\circ} \mathrm{C}^{-1}$ in the high 

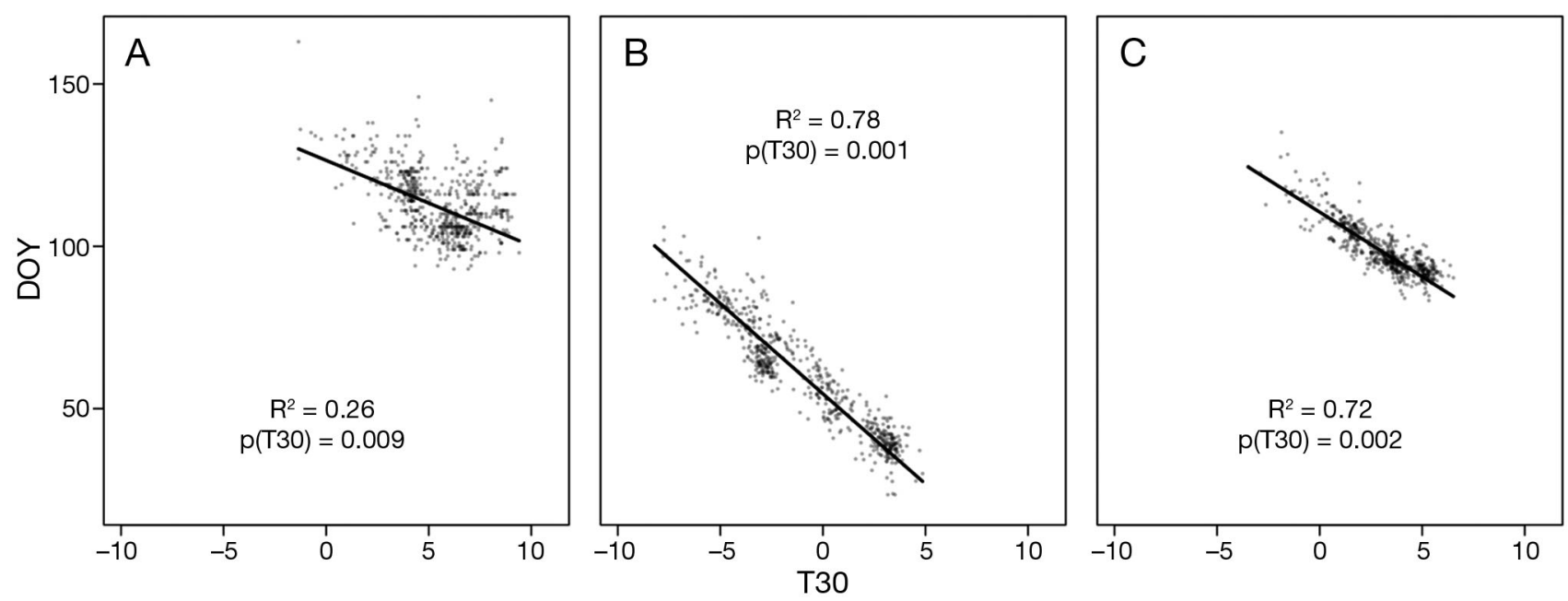

Fig. 4. Relationships between temperature (T30, the temperature average over the $30 \mathrm{~d}$ prior to the tenth quantile of the respective observational dates) and phenology: (A) European spruce bark beetle Ips typographus first flight activity (first beetle day, FBD), (B) common snowdrop Galanthus nivalis first flowering and (C) horse chestnut Aesculus hippocastanum leaf bud burst with mean

montane belt for FBD, and a gradual shift from $-4.0 \mathrm{~d}$ ${ }^{\circ} \mathrm{C}^{-1}$ in the colline and submontane belt to $-3.9 \mathrm{~d}^{\circ} \mathrm{C}^{-1}$ in the high montane belt for A. hippocastanum. The shift in the response of G. nivalis was more pronounced, with a gradual shift from -5.5 to $-7.1 \mathrm{~d}^{\circ} \mathrm{C}^{-1}$ from the colline and submontane to the high montane belt (Fig. A1 in the Appendix).

\subsection{Influence of temperature threshold for $T_{D D}$ calculation on forecasting skills}

$\mathrm{T}_{\mathrm{DD}}$ was dependent on the threshold mean temperature, and the alternative run with the threshold temperature set to $5^{\circ} \mathrm{C}$ resulted in higher $\mathrm{T}_{\mathrm{DD}}$ values, with a mean of $82.3 \mathrm{dd}$ with a $95 \%$ confidence interval of $77.4-85.5$ dd. General model characteristics were relatively robust to changes in threshold temperature. Reduction of RSS with the phenology-based model still amounted to $3 \%$, and the difference in $\mathrm{R}^{2}$ for the validation period increased to $25 \%$. Median RE and CE differences were smaller (0.09 in both cases) for a temperature threshold of $5^{\circ} \mathrm{C}$, indicating slightly better forecasting skills for the lower temperature threshold. However, the forecasting bias stayed constant at a median forecast of $2.00 \mathrm{~d}$ too late.

\subsection{Effect of mixed modelling on forecasting skills of the phenology model}

Neglect of the longitudinal characteristics of the data set for the phenology-based model led to a dif- ferent and less robust choice of the phenological phases: Acer platanoides (first flowering) was chosen in $86 \%$ of the cases, Betula pendula (leaf budburst) was chosen in $62 \%$ of the cases, and only $44 \%$ of the models included both phases together. The forecasting skills, however, were superior to the mixed effects model, with higher values for $\mathrm{RE}$ and $\mathrm{CE}$ (median differences of $0.14, \mathrm{p}<0.001$ ). In contrast to the full model, the simpler phenology model without mixed effects had a bias towards a later forecast $(\mathrm{p}<$ 0.001 ) of $0.93 \mathrm{~d}$.

\section{DISCUSSION}

Large-scale phenological monitoring of bark beetles is a challenge due to the high variability in abundance of these insects between different sites and years. Spring development and first flight activity is primarily dependent on air temperature; nevertheless, microclimatic conditions also play a major role (Annila 1969). In contrast to previous studies that are characterised by accurate, low-interval trap counts or involve microclimatic measurements (e.g. Lobinger 1994, Baier et al. 2007), our data are of low temporal resolution, but are based on a huge sample size and cover a large geographical and altitudinal range (the latter of more than $1300 \mathrm{~m}$ ). In terms of spatial coverage, our study is comparable to a 2006-2010 study in Sweden based on pheromone traps and tree felling (Öhrn et al. 2014). In our study, we used trap count data from a large area of distributed forest sites across Bavaria, which is unique compared to previ- 
ously published studies on the phenology of bark beetles.

Both FBD and plant phenology showed a clear relationship to spring temperatures, with increasing mean temperatures leading to earlier emergence of bark beetles and earlier observations of phenological phases such as first flowering or leaf budburst. Temperature sensitivity of FBD and leaf budburst of Aesculus hippocastanum were furthermore robust across altitudinal belts. Our findings of temperature sensitivities for Galanthus nivalis first flowering and $A$. hippocastanum leaf budburst of -5.5 and $-4.0 \mathrm{~d}^{\circ} \mathrm{C}^{-1}$, respectively, are consistent with findings based on long-term observations. For example, a very similar lapse rate for G. nivalis of $-5.3 \mathrm{~d}^{\circ} \mathrm{C}^{-1}$ was reported by Menzel (2003), whereas Sparks et al. (2000) detected a lower rate of $-3.4 \mathrm{~d}^{\circ} \mathrm{C}^{-1}$ for an independent data set. For A. hippocastanum, Menzel (2003) reported a sensitivity of $-4.6 \mathrm{~d}^{\circ} \mathrm{C}^{-1}$ based on long-term observations, while Sparks et al. (2000) reported $-4.9 \mathrm{~d}^{\circ} \mathrm{C}^{-1}$. Leaf budburst of $A$. hippocastanum is temporally closer to FBD, which explains the higher contribution to the phenology-based prediction model in terms of a greater effect size.

Since entomological studies usually employ thermal sums to describe temperature requirements for phenological phases, there is, to our knowledge, no published reference sensitivity for FBD to temperature. Our study is based on a large sample size with comprehensive spatial coverage; moreover, the results for sensitivity in plant phenology indicate a good approximation of temporal trends with the chosen space-for-time approach. Thus, our results permit the conclusion that warmer spring temperature leads to earlier spring flight activity of Ips typographus by about $2.6 \mathrm{~d}^{\circ} \mathrm{C}^{-1}$ for the investigation area. The weaker correlation between FBD and mean temperatures in comparison to those for the plant phenological phases can at least in part be explained by the inaccuracy and bias of FBD introduced by infrequent trap counts. The sensitivity, however, was influenced only marginally by this inaccuracy.

Onset dates for phenological phases are integrative measures for environmental conditions that have to be fulfilled before physiological and morphological processes can operate at the organism level. In many studies, air temperature sums or means prior to the observational dates are employed as the sole proxy for a possibly complex control chain. The modelling approach in this study is based on the assumption that plant phenology as an integrative parameter can be used to track another integrative parameter, such as bark beetle phenology.
The comparison of a thermal sum-based approach and the phenology-based approach clearly show the superior forecasting skills of the latter, both in terms of predictive power and in terms of forecasting precision. For the forest practitioner, this means that the observation of merely 2 phenological phases can lead to more precise management planning with less effort. We showed that the superiority of a phenology-based approach is robust against temperature thresholds for computing the $\mathrm{T}_{\mathrm{DD}}$ and also against the integration of random effects into the phenology model. Mixed effects modelling, however, led to more robust estimates of the best phenological phases and to less bias in forecasting dates.

Being able to forecast the timing of swarming is especially important in the context of climate change. Spring warming will allow increased voltinism of the beetles before hibernation (bi- or multivoltinism) and thus facilitate rapid population growth and mass propagation (van Asch \& Visser 2007). However, the effect of this switch to the initiation of an additional generation on population dynamics (Jönsson et al. 2009) is not without risk. Uncompleted maturation feeding or overwintering as larvae or pupae (when a complete development of a second generation is not possible) may reduce the fitness of beetles in spring and thus population growth (Dworschak et al. 2009). As shown by Marini et al. (2012), higher temperatures may also result in an increasing infestation pressure on forests and in an upward shift of the altitudinal outbreak range (Walther et al. 2002). It is very likely that more frequent and more extreme events (natural disturbances such as drought, heat waves and storms) will add significantly to bark beetle population growth. Under these different pressures, the urgent need for continuous and spatially-dense bark beetle monitoring by pheromone traps is obvious. A more rigorous monitoring scheme would also allow an exploration of refined phenological forecasting models for other key events in bark beetle population dynamics.

Acknowledgements. We thank the Bayerische Landesanstalt für Wald und Forstwirtschaft (LWF) for cooperation and providing the bark beetle data and the German Meteorological Service for the meteorological data. This study received support from the Nationalpark Bayerischer Wald and the Technische Universität München, Institute for Advanced Study, funded by the German Excellence Initiative. The research leading to these results received funding from the European Research Council under the European Union's Seventh Framework Programme (FP7/2007-2013)/ ERC grant agreement no. 282250. 


\section{LITERATURE CITED}

Annila E (1969) Influence of temperature upon the development and voltinism of Ips typographus L. (Coleoptera, Scolytidae). Ann Zool Fenn 6:161-208

Baier P, Pennerstorfer J, Schopf A (2007) PHENIPS - a comprehensive phenology model of Ips typographus (L.) (Col., Scolytinae) as a tool for hazard rating of bark beetle infestation. For Ecol Manag 249:171-186

Bakke A (1992) Monitoring bark beetle populations: effects of temperature. J Appl Entomol 114:208-211

Bates D, Mächler M, Bolker B, Walker S (2015) Fitting linear mixed-effects models using lme4. J Stat Softw 67:1-48

Beniston M (2004) The 2003 heat wave in Europe: a shape of things to come? An analysis based on Swiss climatological data and model simulations. Geophys Res Lett 31: 2022-2026

Bentz BJ, Régnière J, Fettig CJ, Hansen EM and others (2010) Climate change and bark beetles of the western United States and Canada: direct and indirect effects. Bioscience 60:602-613

Brosinger F, Östreicher S (2009) Die Fichte im Klimawandel. LWF Wissen 63:11-15

Cook E, Briffa K, Jones P (1994) Spatial regression methods in dendroclimatology: a review and comparison of two techniques. Int J Clim 14:379-402

DWD (Deutscher Wetterdienst) (ed) (1991) Anleitung für phänologische Beobachter des Deutschen Wetterdienstes (BAPH). DWD, Offenbach am Main

Dworschak K, Gruppe A, Schopf R (2009) Mortality of the European spruce bark beetle (Ips typographus L.) after hibernation along an altitude gradient. Mitt Dtsch Ges Allg Angew Entomol 17:163-167

Ellenberg H (1996) Vegetation Mitteleuropas mit den Alpen in ökologischer, dynamischer und historischer Sicht, 5th edn. Ulmer, Stuttgart

Ellwood ER, Diez JM, Ibáñez I, Primack RB, Kobori $H_{\text {, }}$ Higuchi H, Silander JA (2012) Disentangling the paradox of insect phenology: Are temporal trends reflecting the response to warming? Oecologia 168:1161-1171

- Faccoli M (2009) Effect of weather on Ips typographus (Coleoptera Curculionidae) phenology, voltinism, and associated spruce mortality in the southeastern Alps. Environ Entomol 38:307-316

Hanewinkel M, Cullmann DA, Schelhaas MJ, Nabuurs GJ, Zimmermann NE (2013) Climate change may cause severe loss in the economic value of European forest land. Nat Clim Change 3:203-207

Harding S, Ravn HP (1985) Seasonal activity of Ips typographus L. (Col., Scolytidae) in Denmark. Z Angew Entomol 99:123-131

Harrington R, Clark SJ, Welham SJ, Verrier PJ and others (2007) Environmental change and the phenology of European aphids. Glob Change Biol 13:1550-1564

> Johnson PCD (2014) Extension of Nakagawa \& Schielzeth's R2GLMM to random slopes models. Methods Ecol Evol 5:944-946

> Jönsson AM, Bärring L (2011) Future climate impact on spruce bark beetle life cycle in relation to uncertainties in regional climate model data ensembles. Tellus Ser A Dyn Meterol Oceanogr 63:158-173

Jönsson AM, Appelberg G, Harding S, Bärring L (2009) Spatio-temporal impact of climate change on the activity and voltinism of the spruce bark beetle, Ips typographus. Glob Change Biol 15:486-499
Kahle D, Wickham H (2013) ggmap: spatial visualization with ggplot2. R J 5:144-161

Kölling C, Dietz E, Falk W, Mellert KH (2009) Provisional climate-risk maps as a tool for climate adapted forest conversion in Bavaria. Forst Holz 64:40-47

Kuznetsova A, Bruun Brockhoff P, Bojesen Christensen RH (2013) lmerTest: tests in linear mixed effect models (lmer objects of lme4 package). R package version 2.0-29. http: //CRAN.R-project.org/package=lmerTest

Lefcheck J, Casallas JS (2014) rsquared.glmm - R-squared for generalized linear mixed effects models. Version 0.2-4. Available at https://github.com/jslefche/rsquared.glmm

Lindner M, Maroschek M, Netherer S, Kremer A and others (2010) Climate change impacts, adaptive capacity, and vulnerability of European forest ecosystems. For Ecol Manag 259:698-709

$>$ Lobinger DG (1994) Die Lufttemperatur als limitierender Faktor für die Schwärmaktivität zweier rindenbrütender Fichtenborkenkäferarten, Ips typographus L. und Pityogenes chalcographus L. (Col., Scolytidae). Anz Schädlkd Pflanzenschutz Umweltschutz 67:14-17

- Marini L, Ayres MP, Battisti A, Faccoli M (2012) Climate affects severity and altitudinal distribution of outbreaks in an eruptive bark beetle. Clim Change 115:327-341

> Menzel A (2003) Plant phenological anomalies in Germany and their relation to air temperature and NAO. Clim Change 57:243-263

> Menzel A, Sparks TH, Estrella N, Koch E and others (2006) European phenological response to climate change matches the warming pattern. Glob Change Biol 12: 1969-1976

Mosteller F, Tukey JW (1977) Data analysis and regression. Addison-Wesley, Reading, MA

Müller-Westermeier G (1995) Numerisches Verfahren zu Erstellung klimatologischer Karten. Berichte des deutschen Wetterdienstes No. 193. Deutscher Wetterdienst, Offenbach am Main

Nakagawa S, Schielzeth H (2013) A general and simple method for obtaining $\mathrm{R}^{2}$ from generalized linear mixedeffects models. Methods Ecol Evol 4:133-142

Öhrn P, Långström B, Lindelöw Å, Björklund N (2014) Seasonal flight patterns of Ips typographus in southern Sweden and thermal sums required for emergence. Agric For Entomol 16:147-157

Parmesan C, Yohe G (2003) A globally coherent fingerprint of climate change impacts across natural systems. Nature 421:37-42

R Development Core Team (2015) R: a language and environment for statistical computing. R Foundation for Statistical Computing, Vienna

- Rouault G, Candau JN, Lieutier F, Nageleisen LM, Martin JC, Warzée N (2006) Effects of drought and heat on forest insect populations in relation to the 2003 drought in Western Europe. Ann Sci 63:613-624

> Roy DB, Sparks TH (2000) Phenology of British butterflies and climate change. Glob Change Biol 6:407-416

Schelhaas MJ, Nabuurs GJ, Schuck A (2003) Natural disturbances in the European forests in the 19th and 20th centuries. Glob Change Biol 9:1620-1633

> Schlyter P, Stjernquist I, Bärring L, Jönsson AM, Nilsson C (2006) Assessment of the impacts of climate change and weather extremes on boreal forests in northern Europe, focusing on Norway spruce. Clim Res 31:75-84

Sparks TH, Jeffree EP, Jeffree CE (2000) An examination of the relationship between flowering times and temperature 
at the national scale using long-term phenological records from the UK. Int J Biometeorol 44:82-87

Spekat A, Enke W, Kreienkamp F (2007) Neuentwicklung von regional hoch aufgelösten Wetterlagen für Deutschland und Bereitstellung regionaler Klimaszenarios auf der Basis von globalen Klimasimulationen mit dem Regionalisierungsmodell WETTREG auf der Basis von globalen Klimasimulationen mit ECHAM5/MPI-OM T63L31 2010 bis 2100 für die SRES Szenarios B1, A1B und A2. Umweltbundesamt, Potsdam

Spellmann H, Sutmöller J, Meeseburg H (2007) Risikovorsorge im Zeichen des Klimawandels. Vorläufige Empfehlungen der NW-FVA am Beispiel des Fichtenanbaus. AFZ Wald 23:1246-1249

van Asch M, Visser ME (2007) Phenology of forest caterpillars and their host trees: the importance of synchrony.
Annu Rev Entomol 52:37-55

- Walther GR, Post E, Convey P, Menzel A and others (2002) Ecological responses to recent climate change. Nature 416:389-395

Wermelinger B, Seifert M (1998) Analysis of the temperature dependent development of the spruce bark beetle Ips typographus (L) (Col., Scolytidae). J Appl Entomol 122: 185-191

Wickham H (2009) ggplot2: elegant graphics for data analysis. Springer, New York, NY

Zang C, Biondi F (2015) treeclim: an R package for the numerical calibration of proxy-climate relationships. Ecography 38:431-436

Zumr V (1982) Flight activity of the spruce bark beetle, Ips typographus, to pheromone traps (Coleoptera, Scolytidae). Acta Entomol Bohemoslov 79:422-428
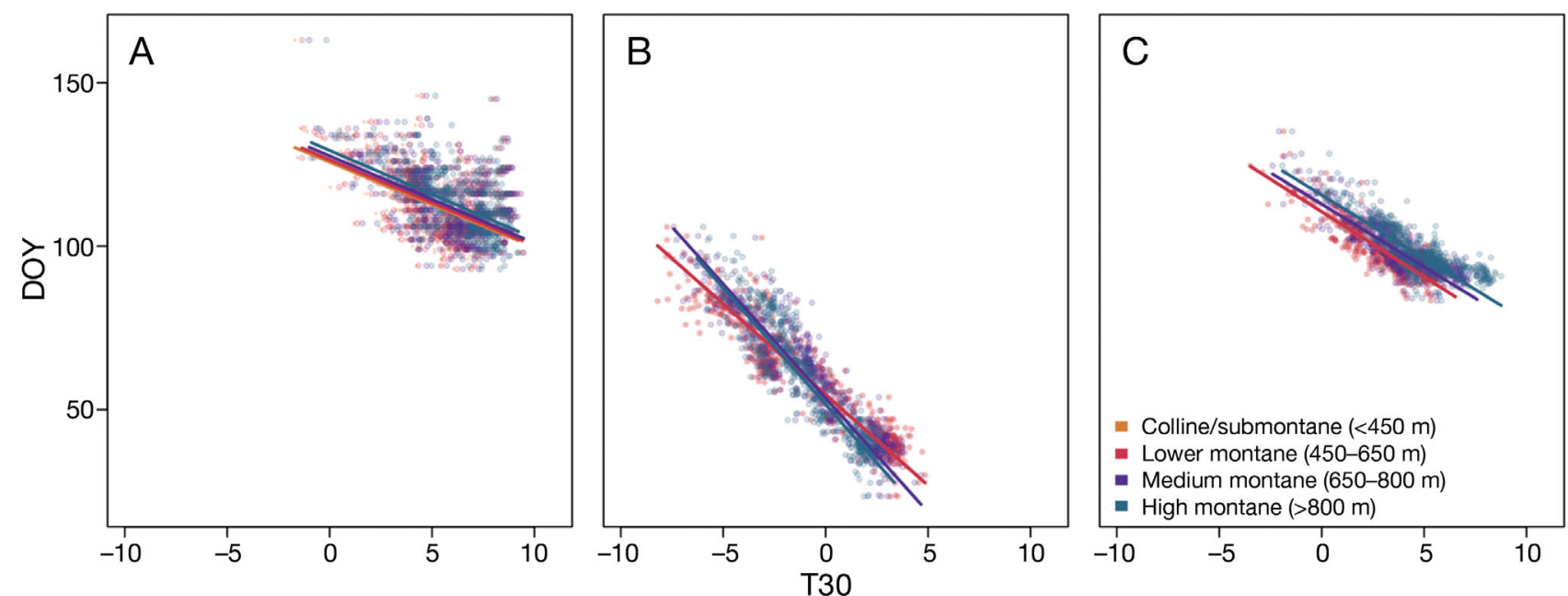

Appendix. Fig. A1. Relationships between (A) bark beetle first flight activity (first beetle day), (B) common snowdrop Galanthus nivalis first flowering and (C) horse chestnut Aesculus hippocastanum leaf budburst, with mean temperature (T30, the temperature average over the $30 \mathrm{~d}$ prior to the tenth quantile of the respective observational dates). Observations were stratified into altitudinal belts, and T30 was computed specifically for each altitudinal belt

Editorial responsibility: Mauricio Lima, Santiago, Chile
Submitted: July 30, 2014; Accepted: September 25, 2015

Proofs received from author(s): October 30, 2015 